\title{
A Entrevista Cartográfica na Investigação da Experiência Mnêmica
}

\author{
Eduardo Passos \\ Universidade Federal Fluminense, RJ, Brasil. \\ Leticia Maria Renault de Barros \\ Universidade Federal Fluminense, RJ, Brasil.
}

\author{
André do Eirado \\ Universidade Federal Fluminense, RJ, Brasil. \\ Christian Sade \\ Universidade Federal Fluminense, RJ, Brasil.
}

Resumo: Este artigo apresenta uma pesquisa que objetivou comparar metodologias de pesquisa no campo de estudos da memória, no contexto da retomada do tema da consciência e da experiência na Psicologia cognitiva. Assumindo a perspectiva da teoria da enação de Francisco Varela, entendemos que a experiência não é representação de um mundo pré-dado e que sujeito e objeto são coemergentes. O projeto pretendeu comparar as metodologias quanto às suas possibilidades de acesso à experiência. Para tanto, buscamos comparar uma metodologia de terceira pessoa e uma de primeira pessoa no estudo do fenômeno denominado "falsa lembrança". Utilizamos como metodologia de terceira pessoa um protocolo experimental baseado num experimento de desinformação formulado por Belli e, como metodologia de primeira pessoa, desenvolvemos uma técnica de entrevista inspirada na Entrevista de Explicitação de Pierre Vermersch, denominada entrevista cartográfica. Este artigo apresenta alguns dos resultados desse projeto, sobretudo no que diz respeito ao acesso à experiência de lembrar nas entrevistas. A metodologia de terceira pessoa mostra restrições no acesso à experiência mesma do lembrar, uma vez que ela não se refere diretamente à experiência, mas às variáveis de "tempo de reação" e "escore de acertos" a questões pré-definidas. Há, portanto, uma tendência judicativa em relação à experiência subjetiva. Já nas entrevistas, pudemos observar diferentes movimentos de maior ou menor acolhimento da coemergência. Definimos três categorias como indicadores desses movimentos: automatismo, controle egoico e autonomia coletiva, que são descritas no artigo.

Palavras-chave: Metodologia, Entrevista, Cognição, Falsa Lembrança, Experiência. 


\title{
Cartographic Interviews in the Investigation of Remembering
}

\begin{abstract}
This article presents a study aimed at comparing research methodologies in the field of memory studies, in the context of the rediscovery of consciousness and experience in cognitive psychology. Adopting the enaction theory perspective of Francisco Varela, we understand that the experience is not a representation of a pre-given world and also that the subject and the object are co-emergent. The project intended to compare the methodologies in respect of their ability to access the experience. Therefore, we aimed to compare a first-person methodology with a thirdperson methodology in the study of a phenomenon called "false memory". As a third-person methodology, we used an experimental protocol based on an experiment on misinformation developed by Belli. As a first-person methodology, we developed an interviewing technique inspired by the Explicitation Interview of Pierre Vermersch called "cartographic interview". This article presents some of the results of the project, mainly with respect to the access to the remembering experience in the interviews. The third-person methodology has limitations in the access of the experience itself, insofar as it does not refer directly to the experience, but to the "reaction time" and "score of hits" variables in predetermined questions. Consequently, there is a judicative tendency towards the subjective experience. In the interviews, instead, we could observe different movements to embrace co-emergence, to a greater or lesser degree. We defined three categories as indicators of these movements: automatism, egoic control, and collective autonomy, which are described in this article.
\end{abstract}

Keywords: Methodology, Interview, Cognition, False Memory, Experience.

\section{La Entrevista Cartográfica en la Investigación de la Experiencia Mnémica}

Resumen: Este artículo presenta una investigación que objetivó comparar metodologías de investigación en el campo de estudios de la memoria, en el contexto de la retomada del tema de la conciencia y de la experiencia en la psicología cognitiva. Asumiendo la perspectiva de la teoría de la enación de Francisco Varela, entendemos que la experiencia no es representación de un mundo pre-dado y que sujeto y objeto son coemergentes. El proyecto pretendió comparar las metodologías en cuanto a sus posibilidades de acceso a la experiencia. Para ello, buscamos comparar una metodología de tercera persona y una de primera persona en el estudio del fenómeno denominado "falso recuerdo". Utilizamos como metodología de tercera persona un protocolo experimental basado en un experimento de desinformación formulado por Belli y, como metodología de primera persona, desarrollamos una técnica de entrevista inspirada en la Entrevista de Explicitación de Pierre Vermersch, denominada entrevista cartográfica. Este artículo presenta algunos de los resultados de este proyecto, sobre todo en lo que se refiere al acceso a la experiencia de recordar en las entrevistas. La metodología de tercera persona muestra restricciones en el acceso a la experiencia misma del recordar, ya que no se refiere directamente a la experiencia, sino a las variables de "tiempo de reacción" y "puntuación de aciertos" a cuestiones predefinidas. Hay, por lo tanto, una tendencia judicativa en relación a la experiencia subjetiva. Ya en las entrevistas, pudimos observar diferentes movimientos de mayor o menor acogimiento de la coemergencia. Definimos tres categorías como indicadores de estos movimientos: automatismo, control egoico y autonomía colectiva, que se describen en el artículo.

Palabras clave: Metodología, Entrevista, Cognición, Falso Recuerdo, Experiencia. 


\section{Introdução}

Este texto é fruto da pesquisa "O paradigma reconstrutivista da memória: um estudo comparativo das metodologias em primeira e terceira pessoa no domínio da Psicologia da Cognição", realizada no Laboratório de Estudos do Comportamento Humano e Animal, do Departamento de Psicologia da Universidade Federal Fluminense (UFF) (Faperj, 2006-2009). $\mathrm{O}$ debate proposto na pesquisa se insere na atual discussão acerca do retorno da consciência como objeto de estudo das ciências cognitivas e visou à comparação entre duas metodologias distintas no que diz respeito à investigação da experiência. As pesquisas atuais acerca da cognição utilizam predominantemente uma metodologia de terceira pessoa, cujo modelo baseia-se na proposição de tarefas e análise das respostas obtidas, principalmente quanto às variáveis "tempo de reação" e "escore de acertos" (Anderson, 2004; Catania, 1999; Kantowitz, Roediger III \& Elmes, 2006). Desta maneira, a experiência vivida pelo sujeito não é diretamente abordada. O objetivo das metodologias em primeira pessoa é justamente permitir um acesso direto à experiência vivida (Varela, \& Shear, 1999). A experiência por nós investigada através destas duas metodologias consistiu no fenômeno das falsas lembranças (Loftus, \& Hoffman,1989; Belli, 1989; Schacter, 2003; Stein, 2010). Desse modo, o comportamento de lembrar pôde ser estudado não apenas como resultado observável de uma tarefa de memória (método de terceira pessoa), mas também como um processo ou uma ação cognitiva que pode vir a estar disponível como experiência consciente para o participante, mediante uma metodologia que desenvolvemos nesta pesquisa e que denominamos entrevista cartográfica (Renault, Passos \& Eirado, 2016; Tedesco, Sade, \& Caliman, 2013). Trata-se de uma técnica de entrevista inspirada na entrevista de explicitação (Vermersch, 1994) e baseada no conceito de enação (Varela, 1988) e na pragmática da epoché proposta por Depraz, Varela \& Vermesch $(2003,2006)$.

Segundo o conceito de enação, o sujeito e o objeto de uma experiência cognitiva constituem-se mutuamente, havendo, portanto, uma dimensão performativa da experiência cognitiva, ou a gênese da realidade na experiência (Despret, 2004; Passos, \& Eirado, 2009; Petitmengin, 2006, 2007; Varela, Thompson \& Rosch, 2003). Visamos nesse texto destacar os recursos metodológicos e técnicos para o acesso à experiência, tal como definida acima, e suas consequências. Particu- larmente, ao longo das entrevistas, queríamos observar como a investigação da experiência pode contribuir para demonstrar a inseparabilidade entre sujeito e objeto do conhecimento, bem como a autonomia da cognição, definida na abordagem enativa de Varela, o que não ocorre quando a pesquisa se restringe ao uso de metodologias de terceira pessoa.

Nossa preocupação não pode ser considerada fora do campo mais geral dos estudos da subjetividade, campo no qual a posição do sujeito ou participante de uma investigação não pode ser desprezada sem o risco de se perder a singularidade do tema investigado. Tomar a experiência como tema de investigação nos obriga a incluir a posição daquele que investigamos em sua comunidade de direito com aquela daquele que investiga. Tal comunidade se exprime na esfera das demandas e desejos que são matéria não completamente representável, mas que permitem a sintonia (no sentido da radiodifusão) entre as frequências dos mundos do investigador e do participante.

\section{Do experimento à experiência: o fenômeno das falsas lembranças}

Há um desafio contemporâneo em retomar o estudo da experiência. O que significa tomar a experiência como objeto e não como um meio para aceder ao objeto do conhecimento psicológico? A experiência foi abandonada em prol do experimento que é uma experiência mediadora e não tematizada enquanto tal. A experiência reduzida ao seu aspecto de experimento científico comparece nos protocolos de pesquisa a partir da atividade de controle de variáveis. Nesse sentido, a singularidade da experiência daquele que experimenta no experimento (tanto o participante quanto o próprio investigador) é desprezada como dado significativo para o conhecimento científico.

Nos debates atuais, muito esforço já foi despendido para alçar a experiência singular ao estatuto de dado científico relevante e objeto de conhecimento (Overgaard, Gallagher \& Ramsøy, 2008; Petitmengin, 2009). Porém, resta ainda uma questão importante a ser considerada e que coloca a experiência no lugar da dinâmica de gênese do próprio dado, a saber: não seria a experiência também o plano de coemergência do mundo experimentado e daqueles que o experimentam? Essa pergunta não é retórica ou despropositada, pois nós consideramos que todo acesso à realidade é uma experiência de realidade, ou seja, qualquer descrição da realidade, seja ela física ou psí- 
quica, depende integralmente da experiência e dos atos que se dão em sua dinâmica de gênese, seu processo de transformação. Nesse sentido, objetividade e subjetividade estão em uma relação recursiva ou circular. Para que uma experiência de realidade seja expressa em termos unicamente objetivos, por exemplo, é preciso se colocar de um ponto de vista que não considere a recursividade e, portanto, também oculte o processo de gênese em curso.

Em outro texto, propusemos a distinção entre experiência vivida e experiência prerrefletida (Eirado et al., 2010). A palavra experiência pode assumir um espectro grande de sentidos, mas existem dois que referenciam os demais. $\mathrm{O}$ primeiro diz respeito à noção usual de "experiência de vida" que vai desde a enumeração de situações pelas quais se passou, até o conhecimento ou a sabedoria que advêm da reflexão sobre a própria vida vivida. $\mathrm{O}$ segundo envolve o sentido prerrefletido e ontológico de experiência como coemergência de si e do mundo, englobando a questão da experiência em primeira pessoa, interesse da retomada contemporânea do introspeccionismo (Varela, 1996; Varela, Thompson, \& Rosch, 2003). Se a experiência prerrefletida é capaz de exprimir a dinâmica de gênese, a experiência vivida, entretanto, é importante como via de acesso à primeira. Há vários motivos para se considerar a importância de explorar a dimensão prerrefletida por meio da experiência vivida. Destacamos três que nos parecem mais relevantes: 1) a experiência vivida é instável e não pode ser controlada tão facilmente e inteiramente como são a observação externa ou experimento; 2) consequentemente, sendo o sentido da experiência vivida sempre variável, o estabelecimento do que se julga como real/irreal, certo/errado, bom/mau, é passível de ressignificação reiterada, fazendo com que essa experiência forme um círculo, onde o que é dado e o que está se dando se constituam mutuamente em uma rede de conversação (Maturana, 1997) polifônica; 3) a experiência vivida porta uma densidade que não se expressa satisfatoriamente a partir do ponto de vista de terceira pessoa, no qual a rede de conversação se oculta e o "diálogo" se dá na relação de um sujeito separado de um objeto.

A estes dois sentidos de experiência, temos que acrescentar o experimento científico em sua posição intermediaria. É importante voltar à natureza do experimento porque nele se esconde um ato cujo efeito é o de frequentemente ver a experiência como dado e, por consequência, a gênese do dado fica oculta. No experimento em Psicologia, muitas vezes, o que se chama de dado são escores de respostas e tempos de reação; aspectos qualitativos e intensivos na experiência, que sempre se dão como processos, ficam perdidos (Jack, \& Roepstorff, 2002; Lutz, \& Thompson, 2003). No texto "Memória e alteridade" (Eirado et al., 2006) mostramos que o ponto de vista de terceira pessoa usado nos experimentos científicos está estruturado segundo o ato do julgamento. Para julgar é sempre necessário ter concluído um processo que resultou em dados ou evidências. $O$ juiz não pode concluir sua tarefa enquanto um processo estiver em curso, nesse sentido, o momento de julgar é aquele em que um dado conclui um processo. Assim como no tribunal, aquele que sofreu a ação a ser julgada desaparece para deixar apenas o autor e o tribunal, também no experimento o participante em sua experiência singular desaparece para ceder lugar apenas aos escores e ao ponto de vista judicativo da ciência.

Através da discussão do lugar do experimento científico em relação aos sentidos da experiência, nós podemos ver como a função de controle do experimento se desdobra em outras duas funções, a de regulação e a de julgamento. Essa ação judicativa, por tomar da realidade somente a sua dimensão de dado, reduz a experiência à sua face objetivada como resposta ou escore. Tal redução pode fechar o acesso à experiência, não considerando as demandas e interesses do participante da pesquisa: aquele que experimenta em um experimento, seja ele o pesquisado ou o próprio pesquisador. Na atividade de pesquisa laboratorial, o participante, na relação com o pesquisador, é "colocado" na posição exclusiva de fonte de dados para o experimento, formando o que Despret (2011) designou de "pacto de dupla ignorância": investigador e participante "colaboram" com a suposta objetividade do experimento; o pesquisador faz como se não se interessasse pelas demandas e interesses do pesquisado e esse faz com que o primeiro desconsidere seu ser cognitivo e interessado nas possíveis hipóteses testadas. Já em nosso campo de investigação, esse "faz de conta" não pode ser sustentado, pois a abertura para as demandas e interesses dos dois lados é requisito ao encaminhamento do processo de investigação que é forçado a considerar a experiência tanto do pesquisador quanto dos participantes da pesquisa.

O fenômeno das falsas lembranças nos fornece um interessante caso desse problema da redução da expe- 
riência a sua face objetivada. Nele, um sujeito tem uma lembrança que, objetivamente, não corresponde ao que foi convencionado no coletivo social como tendo acontecido (vide: Schacter, 2003; Stein, 2010). Inicialmente, este fenômeno estudado pela pesquisadora americana Elisabeth Loftus foi designado "nova lembrança" (new memory) (Loftus, \& Hoffman, 1989). Posteriormente, a autora passou a enfatizar o termo falsa lembrança (Loftus, 1997). Do ponto de vista da experiência subjetiva de lembrar, a nova lembrança, afirmaram Loftus e Hoffman (1989), tem a mesma velocidade de acesso e apresenta o mesmo grau de confiança, não diferindo, portanto, nesse aspecto, de uma lembrança dita verdadeira. Uma nova lembrança é, deste modo, uma lembrança experimentada como verdadeira, mas que não corresponde a um determinado evento passado.

O debate em torno do fenômeno das novas lembranças implicou, então, dizer que construímos a nossa experiência passada. Nota-se que essa questão produziu problemas para funções sociais importantes, tais como a prática do testemunho tanto no tribunal quanto fora dele, assim como a prática da promessa na vida cotidiana. Esta problemática tornou necessária uma mudança de ênfase de Loftus ao cunhar o termo falsa lembrança. Com essa escolha terminológica, a Psicologia da cognição tenta manter o acordo social vigente em torno da função da memória: representar o passado. A acurácia e a confiança na capacidade de representação de uma lembrança se tornam, então, os aspectos mais relevantes do fenômeno mnêmico para Loftus, em detrimento de interações culturais e sociais (Brown, \& Reavey, 2015). Como destacam Middleton e Brown: "a 'memória' não deve ser considerada como uma função psicológica semelhante a qualquer outra. Ao contrário, ela é um lócus crucial onde questões de identidade pessoal e de ordem social são negociadas" (2006, p. 73).

Um problema foi deixado de fora por Loftus: qual é o estatuto da experiência mnêmica? Para nós, fica claro, a partir da leitura dos autores, que o estatuto da experiência mnêmica não é de representação do passado, e sim de invenção (ou, diríamos, enação) (Eirado et al., 2010). Aquele que lembra aparece através de um ponto de vista singular que emerge com o lembrar.
Assim, o ponto de vista da experiência daquele que lembra de um abuso sexual, por exemplo, faz aparecer um sujeito que se vê como abusado e que designa um outro como autor do abuso. Para a justiça, a acurácia dessa lembrança importa, pois se pode evitar que um inocente seja preso. Mas, independentemente da sua fidedignidade, esta lembrança efetivamente transforma a história pessoal do sujeito e o que ele toma como sendo o mundo e ele mesmo. O caráter criativo desta experiência de lembrar não está apenas em seu processo de constituição, mas, sobretudo, nos seus efeitos, ou seja, no fato de que expressa a criação do próprio sujeito que lembra (sujeito que se sente abusado) e do mundo no qual ele se insere (mundo vivido como abusador). Sujeito e mundo coemergem.

Ora, além da demanda do tribunal, que se refere ao fato passado (supostamente representado), deve-se levar em consideração também aquilo que se põe como experiência (presente) para aquele que lembra. Como destacam Reavey e Brown (2006), retomando o trabalho de Ian Hacking, a Psicologia moderna concebe a memória a partir do que John Locke designou como forensic self: práticas jurídicas e muitas práticas terapêuticas convocam uma identidade subjetiva (o "eu forense") capaz de testemunhar a realidade de eventos passados e extrair suas consequências para o presente. Assim, ainda que do ponto de vista da demanda do tribunal essa mudança de ênfase possa ser justificada, do ponto de vista da experiência subjetiva ela se mostra problemática, posto que a experiência (em seu sentido ético-político, de criação de si e de mundo) passou a ser menos enfatizada em favor do estudo da acurácia e do controle da atividade da memória.

Considerando, então, os dois sentidos da experiência, sobretudo seu sentido de gênese (experiência prerrefletida), buscamos desenvolver uma estratégia de investigação que não reproduzisse o modelo do tribunal. Essa estratégia devia permitir: 1) o acesso à experiência como gênese de si e do mundo; 2) a definição de uma dimensão coletiva e comum da experiên$\mathrm{cia}^{1}$. Veremos a partir de agora, portanto, como a pesquisa que realizamos acerca da experiência mnêmica nos permitiu explorar e desenvolver esses dois pontos.

${ }^{1}$ Com relação ao primeiro ponto, no artigo "Estratégias de pesquisa no estudo da cognição: o caso das falsas lembranças" (Eirado et al., 2010), foi proposta a diferença entre estratégia representacional e estratégia enativa. Essa segunda está sob a égide da noção de coemergência de si e de mundo. O segundo ponto foi indicado, embora não integralmente desenvolvido, nos textos "Cartografia como dissolução do ponto de vista" (Passos, \& Eirado, 2009) e "Cartografar é traçar um plano comum” (Kastrup, \& Passos, 2013). Desenvolver esse último ponto nos implica com a especificidade do campo em que estamos inseridos. No campo da memória, podemos nos reportar ao trabalho de Middleton (2002), que aponta para a construção coletiva da memória e a interdependência entre memórias individuais e coletivas. 


\section{Metodologia}

A pesquisa foi realizada em duas etapas: a experimental e a da entrevista cartográfica. A primeira etapa da pesquisa (o experimento) consistiu na apresentação de um protocolo de pesquisa no computador. Para tanto, elaboramos um experimento que acompanhava a lógica daquele desenvolvido por Belli (1989). Os participantes da pesquisa primeiramente realizavam o protocolo experimental - cujo objetivo é a produção de falsas lembranças - e, uma semana depois, retornavam para uma entrevista. A partir de uma escolha aleatória, dez alunos dos cursos da UFF de História, Ciências Sociais, Letras, Arquivologia e Química, com faixa etária compreendida entre $18 \mathrm{e}$ 25 anos aceitaram o convite para participar da pesquisa. O critério de exclusão dos participantes foi estarem cursando Psicologia.

Na etapa da entrevista começávamos por pedir ao entrevistado que se recolocasse novamente na experiência de ter realizado o protocolo experimental de modo a revivê-la. Nós queríamos usar a entrevista como meio de investigar a experiência dos participantes em ter realizado o protocolo. Não tínhamos a intenção de recuperar um dado subjetivo que tivesse escapado da consciência no momento da realização do protocolo. O objetivo era compreender a experiência do lembrar a partir da exploração da experiência da entrevista no setting e verificar as suas variações em relação à realização do protocolo.

O protocolo dividiu-se em cinco etapas:

1. Exibição aos sujeitos participantes de uma sequência de slides fotográficos que apresentavam uma história, mostrando uma refeição entre amigos. São 65 slides e quatro itens críticos (marca do refrigerante servido, horário indicado por um relógio de parede, palavra que aparece escrita na capa de uma revista, bebida servida pela dona da casa). Os itens críticos são aqueles sobre os quais a narrativa exibida em uma fase posterior do protocolo oferecerá desinformações objetivando a produção de falsas lembranças. Cada item crítico aparece apenas uma vez durante toda a sequência de slides.

2. Realização de uma tarefa distratora durante 10 minutos: um conjunto de cinco problemas lógicos. Nos experimentos de memória a tarefa distratora é usada para evitar que o participante procure rememorar deliberadamente as imagens exibidas entre uma e outra fase do experimento.
3. Exibição aos participantes de uma narrativa contendo "desinformações" sobre os itens críticos que apareciam nos slides. A narrativa descrevia a história exibida, exceto em relação aos quatro itens críticos.

4. Realização de nova tarefa distratora contendo outro conjunto de cinco problemas lógicos, com o mesmo propósito de desviar a atenção do participante em relação aos slides.

5. Teste da memória do sujeito em relação ao evento exibido com 15 questões sobre os slides apresentados, sendo quatro das 15 questões relativas aos itens críticos. Junto a essas questões foi solicitado ao participante que indicasse, no Caderno de Respostas que lhe fora fornecido, o seu grau de confiança (alta, média ou baixa) em relação à sua lembrança. Se, em relação às questões sobre os itens críticos o participante respondesse com base na desinformação oferecida na narrativa e atribuísse à sua resposta alta confiança, falsas lembranças teriam sido produzidas.

Na segunda fase da pesquisa, realizamos a entrevista cartográfica com cada um dos participantes, uma semana após o protocolo experimental.

A formulação da entrevista cartográfica teve como inspiração a entrevista de explicitação, técnica elaborada por Vermersch (1994). O objetivo da entrevista de explicitação interessou à pesquisa acerca das falsas lembranças por uma série de razões: essa entrevista se volta a uma ação e, portanto, dedica-se a criar instrumentos que permitam falar de processos e atos, mais do que de objetos ou dados. Como buscávamos examinar a possibilidade de estudar o fenômeno das falsas lembranças em uma abordagem distinta da representacional, guiamo-nos pelo conceito de enação, contemplando, assim, a cognição como uma atividade na qual coemergem si e mundo. Mais do que estudar as lembranças pelo resultado de uma tarefa, nos interessou estudá-las como uma ação que transcorre de maneiras diferentes em cada caso. Assim, era preciso que adotássemos os meios para abordar o ato mesmo de lembrar, explorando seu processo de constituição.

Em segundo lugar, na entrevista de explicitação busca-se sair da atitude "natural" na qual o entrevistado automaticamente narra sua experiência como se estivesse julgando, ou seja, falando sobre a experiência. Sair dessa perspectiva implica se relacionar de outro modo com a experiência: ao invés de res- 
ponder às perguntas de um entrevistador, a questão é poder exprimir a vivência de um ato cognitivo. A entrevista de explicitação desenvolve, então, técnicas úteis à exploração da dimensão prerrefletida, que, para a abordagem enativa, é intrínseca a toda experiência e implica sempre em reposicionamento dos participantes.

Além disso, a entrevista está interessada na experiência vivida por alguém; a ela, não basta observar a ação realizada ou os resultados obtidos: é preciso consultar aquele que age para que seja efetivamente possível formular alguma compreensão acerca da ação. Ou seja, para a entrevista de explicitação, uma observação distanciada e neutra do trabalho de um cozinheiro, por exemplo, não nos permite compreender o que o leva a saber quando um prato está pronto, ou o quanto mais de tempero é necessário. Há uma perícia na ação de cozinhar que não pode ser detectada em uma mera observação. A entrevista de explicitação assume que é preciso acessar o sentido da ação. Essa técnica de entrevista se apresenta, então, como um instrumento interessante para a investigação dos pontos de vista.

Por fim, a entrevista de explicitação permite distinguir os diferentes tipos de saber: ela não assume de início que todo saber pode ser reduzido a uma formulação abstrata ou a uma regra geral. Por isso, este tipo de entrevista é adequado a uma investigação enativa da atividade cognitiva: ele está voltado ao contexto singular de ocorrência de uma ação. A entrevista, assim, pode se vincular a um estudo da cognição que não busca extrair normas de funcionamento que independeriam de quaisquer circunstâncias.

A entrevista de explicitação busca sustentar uma atitude de abertura, evitando que juízos prévios à própria entrevista determinem o sentido do que é dito. Ao invés de perguntas predefinidas, emprega técnicas de relance, sensíveis à maneira pela qual o próprio entrevistado se exprime. Dentre estas técnicas de relance, estão, por exemplo, questionamentos amplos que evocam a experiência do entrevistado, em lugar de perguntas dirigidas aos saberes teóricos que ele possua (por exemplo, dá-se preferência a perguntar como foi realizar uma ação, em vez de perguntar o que foi feito). Este modo de proceder retoma a prática da epoché que, segundo Husserl, visa à suspensão do juízo sobre a experiência da realidade ou a suspensão da atitude natural tal como foi designado pela fenomenologia (Depraz et al., 2006).
A entrevista de explicitação, contudo, possui algumas especificidades que não se mantiveram inteiramente na técnica de entrevista que utilizamos na pesquisa. A principal delas é relativa à noção de vivido de referência. Para a entrevista de explicitação, a verbalização da ação corresponde à explicitação de um vivido de referência, isto é, à descrição de uma experiência vivida em todos os detalhes de sua ocorrência passada. Por sua vez, ao entrevistarmos os participantes da pesquisa, voltamo-nos diretamente à própria experiência do lembrar, de maneira que a entrevista era guiada não por uma experiência passada tomada como referência, e sim pela experiência vivida no presente da entrevista. A abordagem enativa das falsas lembranças em nossa pesquisa se deu, portanto, com o emprego de um procedimento de entrevista, que denominamos cartográfica (Renault et al., 2016; Tedesco et al., 2013), pois, como um cartógrafo, nossa investigação se caracterizava pelo acompanhamento de processos e movimentos da experiência, o que requeria de nós procedimentos de entrevista igualmente processuais. A cartografia tem sido nossa orientação metodológica no estudo da experiência, quando visamos acompanhar movimentos de constituição do próprio objeto mais do que apreender suas estruturas e estados de coisas. O desafio de investigar processos nos obriga a construir recursos metodológicos eles também processuais (Passos, Kastrup \& Escóssia, 2009; Passos, Kastrup \& Tedesco, 2014).

\section{Resultados e discussão}

Entrevistamos os participantes tendo como ponto de partida o convite a reviver uma experiência (no caso, a de realização do protocolo), isto é, o convite para manter uma relação de presença com a lembrança, de modo que ela se apresentasse de maneira concreta e vívida. Ao retomarmos agora a experiência mesma de entrevistar, destacamos algumas observações que se mostraram importantes para nós. Tais observações constituem apenas um relato do processo de trabalho da pesquisa e não uma sistematização consolidada do procedimento e de seus resultados.

Ao realizarmos as entrevistas, voltamo-nos em grande medida ao estudo de como a entrevista permitia o acesso à experiência em sua dupla dimensão. Algumas indicações relativas à experiência de lembrar nos foram significativas. 
A entrevista nos mostrou que o protocolo experimental deixava de lado a experiência mnêmica. A análise dos dados da pesquisa indicou que as respostas fornecidas ao questionário do protocolo não necessariamente eram a expressão de uma lembrança, o que se constatava nas entrevistas, quando os sujeitos tinham espaço para falar da experiência que viveram ao fazer o protocolo.

A fala de um entrevistado expressa esta posição do sujeito cuja resposta ao questionário confirmava a produção da falsa lembrança. Na entrevista, ele narra sua experiência durante a realização do protocolo na semana anterior e compartilha sua decisão de responder de acordo com a narrativa escrita, embora ele também tivesse a lembrança da imagem do slide:

Quando eu vi a imagem, eu pensei, essa é a hora, 3 horas, vou prestar atenção nesse detalhe, eu acho que vai ser importante para a pesquisa dela. E depois quando eu vi o texto escrito, sei lá, 9 horas, eu pensei: calma aí, tem duas horas aqui. Mas aí obviamente eu não sou dono da verdade, então eu pensei: será que eu esqueci ou confundi? Então vou colocar a segunda.

Os entrevistados puderam compartilhar a produção de conhecimento na pesquisa e revelar a quem até então aparecia como "pesquisador" (e que, neste momento, surgia de uma maneira diferente, como entrevistador) as suas próprias hipóteses relativas ao experimento. $\mathrm{O}$ entrevistado citado acima nos disse, por exemplo, que, ao assistir as imagens do protocolo, buscou prestar atenção a detalhes que ele imaginou que seriam perguntados depois. Outros realizaram o protocolo na suposição de que ele continha "pegadinhas":

Aí tinha uma revista da Veja ali em cima. Aí quando eu vi essa imagem eu pensei alguma coisa né, pensei assim, essa revista Veja não tá aí por acaso [risos]. Aí pensei, ah por que essa... sei lá, casal lê Veja, alguma coisa assim [...].

Mas até tô me lembrando agora de umas... umas questões que achei interessantes, colocadas lá na hora do questionamento, na semana passada, uns detalhezinhos do cenário que... me chamaram a atenção por causa da diferença entre os slides e a narrativa. Não sei se se essa diferença foi proposital [risos]. [...] E se elas não forem propositais? Ainda tive aquele pudor de contrariá-los... vocês que organizam estes experimentos [risos]. Eu escrevi e pronto. Achei que fosse o que fosse... achei melhor colocar de uma vez e... pensar: de repente, essas discrepâncias... pode não ser casual. Ainda fiquei curioso para ver como isso seria desenvolvido, se haveria algum significado, algum objetivo específico. [...] Ainda fiquei pensando [sorri] deve haver gente que... que... ou não percebe ou mais provavelmente vai perceber e não vai escrever.

Os entrevistados nos falavam, enfim, que as respostas que forneceram ao questionário dependiam destas hipóteses formuladas por eles, que, por sua vez, eram inseparáveis de uma atitude frente ao protocolo experimental. Portanto, essas respostas não refletiam necessariamente as suas lembranças referentes ao protocolo. Não podíamos assumir, em nossa pesquisa, que uma resposta tida como "falsa lembrança" no protocolo experimental correspondia de fato à vivência desta experiência pelo participante da pesquisa.

Por outro lado, as lembranças que surgiam na entrevista não necessariamente estavam relacionadas aos itens críticos do protocolo. Muitas vezes, elas se reportavam a outros itens e mesmo a experiências de vida diferentes. Em um caso, o entrevistado descreve a imagem de uma cozinha: disse que ela não era muito grande e que via duas meninas no centro dela, ao lado destas, via uma geladeira branca. Essa lembrança, contudo, não poderia ser reportada ao protocolo, pois nele não havia nenhuma referência à cozinha ou à geladeira. Em outro exemplo, a entrevistadora pergunta: "Como foi a experiência de realizar o protocolo?". O entrevistado hesita e, aos poucos, vai se lançando em uma experiência mnêmica que entrelaça o passado da atividade de ser submetido ao protocolo com o presente da situação da entrevista ela mesma. Ao tentar reviver os slides fotográficos, ele inicialmente responde que "está tudo misturado", "obscuro e confuso". Depois, relata que as lembranças da imagem se misturam com as lembranças da aula que acabara de assistir: o personagem do slide "aparece" na experiência de lembrar com o rosto de um colega com quem ele tinha estado há pouco: 
Eu falei tudo misturado porque me veio uma coisa agora, eu estava assistindo uma aula, sentado num canto da turma, e lá na frente tinha uma pessoa assim, um cara que eu nem sei o nome, eu não conheço muita gente dessa turma não, então tá me vindo esse cara esperando a porta abrir [risos], sabe? [no slide em questão, há um cara próximo à porta], é por isso que eu falei que tá misturado [risos], não tem nada a ver né! [...]. Cara tá impressionante essa coisa desse cara que tava na aula [risos], ele que é o personagem, ele se tornou o personagem dessa... dessa estória de vocês porque eu não lembro do rosto de ninguém...

Embora tais experiências estivessem, para o participante, ligadas à vivência do experimento, elas ultrapassavam tanto a referência supostamente objetiva do protocolo experimental quanto o vivido de referência que procuramos estabelecer de início. As "falsas lembranças" especificadas pelo protocolo não eram, assim, necessariamente importantes na experiência do entrevistado, isto é, elas não necessariamente faziam sentido como tais. Outras vivências, contudo, faziam sentido para o entrevistado e por isso eram exploradas na entrevista. Tais decisões acerca da condução da entrevista só podiam ser tomadas caso a caso, através do compartilhamento da experiência do entrevistado por parte do entrevistador. Constatamos, portanto, a impossibilidade de circunscrever as lembranças de antemão, como entidades estanques. A experiência de entrevista não nos autorizava a desmembrar as lembranças umas das outras, determinando quais eram referentes ao protocolo e quais não eram. Não nos era possível fazer uma comparação item a item entre o protocolo experimental e a entrevista.

A entrevista constituiu-se para nós como um instrumento para explorar a experiência de lembrar, mesmo quando ela se apresentava de maneira não usual, não voltada à resolução de uma tarefa. Uma resposta que, no questionário, é tida como esquecimento, mostrava-se na entrevista como um modo singular de lembrar, que não obedecia, por exemplo, aos critérios de segmentação propostos no protocolo.

Por exemplo, um entrevistado se dá conta de que o protocolo experimental pressupõe itens críticos na condução da experiência mnêmica a ser investigada. $\mathrm{Na}$ entrevista, ele expressa essa sua compreensão fixando-se, no entanto, no que se impunha para ele como um item crítico que não constava da lista dos quatro estabelecidos no protocolo. $\mathrm{O}$ entrevistado queria saber se havia um crucifixo na parede e se ele podia confiar na sua própria memória: "Quero saber se eu não estou maluco". A sua pergunta insistente gera uma surpresa nos pesquisadores, que conduziam a entrevista considerando a existência de outros itens críticos. Responder à indagação do entrevistado era reconhecer a legitimidade da preocupação com o item crítico, mas, por outro lado, não se tratava daquele item crítico. $\mathrm{O}$ entrevistado julga que uma casa de jovens intelectuais (a narrativa que se podia construir a partir dos slides) não apresentaria um símbolo religioso como um crucifixo e ver ou não ver tal objeto torna-se angustiante, um espanto, pois certamente teria percebido algo que faz parte de sua história pessoal. Intrigou-nos o fato de que ele tenha escrito no questionário "não reparei" (com alta confiança!) em resposta à pergunta "Que elemento está na parede ao fundo da mesa?", já que cita, ao mesmo tempo, o fato de o crucifixo virar elemento de pergunta no questionário.

Para nós, a entrevista não se constituía, então, como um instrumento de coleta de dados referentes ao vivido do participante. Ela buscava, antes, criar condições de tornar atuais experiências mais amplas, alargando os pontos de vista iniciais. Desse modo, visávamos uma experiência que não era inteiramente coincidente com a experiência vivida, passível de ser descrita. A experiência vivida era atravessada na entrevista, tornando-se um meio de acessar planos de compartilhamento da experiência. Isto é, a entrevista para nós estava orientada no sentido da dissolução do ponto de vista do observador (Passos, \& Eirado, 2009). Ela se realizava, de fato, como uma vista-do-entre, ou uma entre-vista.

Atravessar uma experiência vivida implicava uma aproximação das experiências de entrevistador e entrevistado. Era preciso aprofundar o compartilhamento de sentido que, para nós, era a condição mesma de toda experiência e que, portanto, estava subjacente desde os primeiros instantes de entrevista. Os pontos de vista não podiam ser pensados fora da experiência que os constituía; sendo assim, a experiência de ser um participante da pesquisa (e tudo o que acompanhava essa experiência, como o sentimento de ser testado, o desejo de colaborar com a pesquisa...) era inseparável da experiência de ser pesquisador. Os dois 
pontos de vista, aparentemente diferentes, surgiam para nós como parte de uma experiência compartilhada. Contudo, na experiência do protocolo experimental, não era possível contemplar esta dimensão comum: cada ponto de vista era vivido como proprietário de sua experiência particular - o participante se sentindo constrangido a responder de determinada maneira ao que lhe era perguntado e o pesquisador assumindo que as dúvidas e expectativas que porventura experimentasse não tinham relação com a situação de aplicação do teste.

Pela entrevista, permitia-se o reconhecimento da base comum da experiência, a partir da qual os pontos de vista emergem. Tal reconhecimento mostrou-se inseparável da própria transformação destes pontos de vista. De uma relação pesquisador/participante, passava-se a uma relação entrevistador/ entrevistado, mais flexível e que, pelas características da própria entrevista, não podia ser definida de antemão. Enquanto na experiência do protocolo, pesquisador e pesquisado não estão na presença um do outro, na entrevista, por outro lado, essa presença se impõe, ou seja, ambos estão durante um determinado tempo em um setting que permite o compartilhamento da experiência. Por exemplo, surgiu, em uma entrevista, a lembrança da disposição existencial com que o protocolo foi feito: a de ter que responder corretamente e de estar sendo avaliado por alguém. Inicialmente, esta lembrança surgia como transparente - como se seu sentido estivesse dado no próprio contexto experimental. Ao mesmo tempo, esta lembrança também se mostrava ligada à situação de entrevista, que igualmente estava sendo vivida como uma situação de teste. Mas, à medida que a entrevista avançava e a vivência desta lembrança era explorada e descrita, ela passou a se evidenciar como um ponto de vista, e, portanto, como uma possibilidade de sentido dentre outras. Dessa forma, notávamos como os pontos de vistas que surgiam não eram propriedades de um eu, mas sim dependentes da experiência do setting de entrevista.

No exemplo do crucifixo, a dúvida angustiante do entrevistado correspondia a uma dúvida dos entrevistadores, que hesitavam responder que de fato havia um crucifixo em um dos slides do protocolo, embora não fosse um dos itens relevantes para o protocolo experimental. Em outro exemplo, a experiência de participar de uma pesquisa de Psicologia entrelaçava entrevistado e entrevistadora de tal maneira que produzia um constrangimento e uma surpresa frente a uma atitude inabitual de acessar a própria experiência:

Acho que tinha uma pessoa de saia indiana.

Saia indiana?

Sei lá, não é saia indiana estas saias que essas meninas quase hippies usam?

Como é que era essa saia?

Não sei como é que era não, agora que tá me vindo azul, é sei lá, poucos detalhes, mas pode ser qualquer cor, só lembro que acho que tinha alguém vestido de saia grande [risos]. Pode ser sei lá laranja, agora me veio azul [risos de novo]. Sei lá, que coisa engraçada, eu nunca fui ao psicólogo, nada disso, sabe, mas achei engraçado, sabe, diferente [resmungos ao fundo].

Adiante, nessa mesma entrevista: "Eu fico até com vergonha, sabia? parece que você é maluco, sei lá, eu não tô acostumado com psicólogo não, por isso que eu tô falando pra caramba... é diferente!”.

\section{Automatismo, controle egoico e autonomia coletiva na experiência da entrevista}

Esta não é uma experiência de entrevista que se realiza sem dificuldades. Há uma série de obstáculos à realização da entrevista como dissolução dos pontos de vista: há àqueles relativos à própria colocação em prática da épochè, mencionados por Depraz et al. (2003; 2006) - como a dificuldade de exercitar o redirecionamento da atenção à experiência, pouco usual em nosso cotidiano e a de lidar com a angústia gerada pelos momentos de vazio e incerteza vivenciados na etapa de acolhimento da experiência como processo.

É importante destacar, ainda, que a dissolução do ponto de vista não pode ser tida como uma meta a ser atingida ou um estado que se alcança, mesmo que momentaneamente. A dissolução nos surge como um horizonte para compreender o que se passa nas experiências de entrevista. Pudemos perceber que as entrevistas que realizamos passavam por momentos de maior ou menor grau de abertura 
à experiência, em sua dupla dimensão. Discriminamos três pontos de referência para nos orientarmos quanto a este grau de abertura (ou de aproximação da dissolução do ponto de vista); trata-se de indicadores de movimentos, e não de estados. Eles serviam ao mesmo tempo para guiar o entrevistador quanto aos relances a serem realizados durante a entrevista e para realizar, em grupo, a análise das entrevistas. Esses indicadores são: automatismo, controle egoico e autonomia coletiva.

No automatismo, responde-se a um mundo que surge como um dado, isto é, não há reflexão acerca do processo a partir do qual surgem si e mundo. $\mathrm{O}$ que aparece é vivido como uma obviedade: não se coloca em questão a experiência que o faz surgir, nem sua relação de dependência com o si mesmo que lhe corresponde. O modo automático de relação com a experiência supõe, assim, gestos imediatos e padronizados de relação com os outros e com o mundo. Trata-se da atitude natural em que comumente nos encontramos, na qual tendemos a perceber e a agir de acordo com os nossos hábitos e tendo como guia os critérios socialmente estabelecidos. Durante as entrevistas, muitas vezes vinham à tona os automatismos que perpassavam nossa relação com as imagens dos slides no protocolo:

Éee, eu percebi que era tipo um encontro de amigos, né! Amigos recebendo amigos em casa, tipo uma recepção, tipo um jantar né! Eee, aí vai seguindo todas aquelas convenções de reuniões com amigos e tal, aí você recebe a pessoa e oferece alguma coisa para beber e tal, aí as pessoas conversam [...]. Mas eu lembro que... essa cena foi quando eu percebi, ah! Eu imaginei o cara deve estar reclamando do som, de alguma coisa, do horário, deve estar tarde, aí era uma imagem assim, o cara na porta, com a porta aberta, e um rapaz de fora apontando para o relógio, com uma cara meio séria, aí eu imaginei, pô, o cara deve estar incomodado com o som.

Bem, eu acho que... a imagem é ele acabando de fechar a porta e se voltando para a sala, ele tava com uma cara de que tinha tomado um esporro e não tinha gostado muito, [...], bem é uma cara de quando você toma um esporro e não gostou, mas, né, infelizmente a pessoa que te deu o esporro tem razão, e que você tem que ficar quieto né!
Fazer o quê? Tava fazendo alguma coisa errada. É só isso. Eu acho que ele tava esboçando algum risinho de deboche, alguma coisa assim.

Em outro exemplo, a entrevistadora pede ao entrevistado para ficar um pouco mais com a imagem em que, segundo ele, as pessoas estavam bebendo alguma coisa. Ela pergunta como é a imagem e ele responde: "Ah! Acho que eles estavam alegres, tavam conversando, tavam curtindo". Também no exemplo citado acima, o entrevistado diz que uma casa de jovens intelectuais não apresentaria um símbolo religioso como um crucifixo.

Em momentos de automatismo na entrevista, o entrevistado responde prontamente, de maneira irrefletida: ao ser perguntado, por exemplo, acerca de suas lembranças, ele fornece uma informação abstrata, adequada ao que é socialmente esperado que se responda. Por outro lado, o entrevistador pode também agir de maneira automática, colocando-se no lugar daquele que deve fazer as perguntas e garantir o cumprimento de uma tarefa.

Não há, neste modo cotidiano de relação com a experiência, uma atenção que esteja de fato voltada ao que se experimenta. Visa-se à realização de tarefas, o que faz com que a atenção recaia unicamente sobre o que a experiência parece representar. Quando se está neste movimento automático, não é possível se deter na singularidade de uma vivência; ela só nos aparece em sua face abstrata e, por isso, de adequação ao que denominamos coletivo-social. O coletivo-social refere-se ao ponto de vista de um observador-padrão, isto é, um ponto de vista pretensamente neutro, de ninguém. Constatamos na pesquisa que este ponto de vista é bem restrito, de modo que o coletivo-social não corresponde a uma dimensão de compartilhamento de sentido e de encontro. Ele é, antes, o ponto de vista em que se está sob o efeito das preconcepções cotidianas e sociais. Trata-se de um ponto de vista apenas pretensamente coletivo ou comum, porque ele se baseia em uma tentativa de exclusão da experiência concreta e de instauração de uma perspectiva única e abstrata. O grau de abertura em relação à experiência é mínimo e o ponto de vista condiciona o surgimento do sujeito diante do mundo de tal maneira que ele não se dá conta da dimensão genética da experiência.

Esta maneira automática de agir, porém, sofre abalos mesmo em nossas vidas cotidianas. A própria 
vivência das lembranças ditas "falsas" perturba essa suposta transparência da experiência, desafiando a atitude natural que toma o mundo como dado. Esta primeira perturbação do ponto de vista automático, do observador distanciado e neutro, leva, então, ao momento que demarcamos como segundo indicador de abertura em relação à experiência: o controle egoico. Neste momento, há maior grau de abertura. Rompe-se a imediata obviedade do mundo e, consequentemente, torna-se preciso realizar uma primeira reflexão. Surge, assim, um sujeito que se apresenta como agente da experiência. Na entrevista, se o automatismo pressupunha uma resposta padrão, em que se age "como se deve" ou se afirma que "é assim que sempre acontece", no controle egoico, alguém se apresenta como responsável pela experiência atual, capaz de justificá-la ("isso está acontecendo porque $e u$ sou assim ou porque $e u$ sempre ajo desta maneira"). Há uma frustração da atitude natural e atenção recai sobre o $\mathrm{eu}$.

Como é essa imagem? Essa imagem... eu acho que é justamente no momento em que tão entrando, em que tão recebendo a visita, né! [baixando o tom da voz] Você pode perceber que eu tô falando tudo estão ${ }^{2}$ [elevando o tom de voz], não falo eles porque eu não lembro exatamente se tinha um casal, se era um casal que visitava, $e u$ faço história, mas a minha memória não é muito boa não [risos].

Eu tô misturando dois ambientes no fundo [baixa o tom de voz] da minha memória, porque no lugar onde estariam uns sofás não tem mais sofá, tem gente sentada em cadeiras normais.

Tá me vindo a imagem da, da... das questões, que tinha as questões de lógica, sei lá o quê, de matemática, sei lá, triângulo, vem na minha cabeça, acho que tinha questão de triângulo, né, mas não sei por que tá me vindo isso? [baixando o tom de voz].

Mas agora veio outra pessoa nada a ver, daquelas que eu te disse que, que aparece na minha cabeça, entendeu? Um maluco, um... a maioria das pessoas que eu tô... que essas imagens que me vem, como eu disse eu tô inventando [...].

Quando surge um momento de controle egoico na entrevista, é porque houve um desvio em relação à posição inicial do sujeito, isto é, em relação ao ponto de vista automático. Trata-se de uma etapa importante na entrevista, porque há, ao mesmo tempo, uma tentativa de recuperação do estado em que as coisas surgem como dadas - resiste-se à dissolução do ponto de vista evocando-se um agente supostamente capaz de controlá-la - e uma oportunidade para aprofundar também esta experiência de $e u$, exercitando a etapa da épochè de reversão da atenção (Depraz et al., 2006). O manejo da entrevista por parte do entrevistador pode ajudar a atravessar este momento de controle egoico em direção à dissolução. Nas entrevistas, o controle egoico ora aparecia em manifestações de estranhamento em relação à experiência que estava sendo vivida, ora em uma tendência a elaborar explicações abstratas, por meio de respostas como: "eu me distraí muito", "não consegui me concentrar direito", "não me pego muito a detalhes", "não consigo me lembrar bem", que podia ser acompanhada de sentimentos de desconforto ou tensão. Mas em ambos os casos a experiência era vivida de maneira mais encarnada e concreta, condição para que se pudesse reconhecê-la em sua dimensão efetivamente comum.

Por fim, os momentos de autonomia coletiva referiam-se àqueles de maior abertura à experiência, na qual esta podia de fato ser sentida em sua dimensão comum ou coletiva, e não como propriedade de um eu. Usualmente autonomia significa autossuficiência ou independência, nos indicando as capacidades individuais de agir e de decidir de acordo com uma experiência vivida de maneira pessoal. Contudo, o que pudemos verificar ao longo das entrevistas é como a autonomia ganha também um sentido não pessoal, já que aponta para os processos de criação de si. Se considerarmos a etimologia da palavra, autonomia significa criar para si suas próprias regras, mas autores contemporâneos radicalizam o sentido desse conceito, definindo um processo de autopoiese no qual o próprio si é também dele efeito (Maturana, \& Varela, 1995; Varela, 1989; 1991). Nesse

${ }^{2} \mathrm{O}$ entrevistado usa o verbo "estão" para indicar algo geral, sem especificar quem está realizando a ação; por não se lembrar com precisão, usa uma forma verbal mais genérica. 
sentido, a autonomia deixa de ser uma propriedade de um indivíduo, já que o indivíduo também emerge como fenômeno da autonomia. De acordo com Varela $(1989,1991)$, a autonomia indica que a experiência não é (pré)determinada por algo externo (ela não é heteronômica), tampouco por algo interno, justamente porque não há tal fundamento a priori: não há uma separação original entre mim e mundo. A autonomia realiza-se na relação de coemegência entre sujeito e mundo, ou seja, como criação simultânea do sujeito e das regras de seu funcionamento. Os momentos de autonomia na entrevista correspondiam, assim, a vivências mais próximas da coemergência. Neste nível, o sentido varia, e lidamos com uma polissemia que equivoca as posições dadas, em função do acesso à dimensão processual e comum da experiência. Por isso, preferimos denominar esse momento de autonomia coletiva.

É nestas ocasiões, que ocorria, por exemplo, de entrevistador e entrevistado compartilharem certo espanto em relação à experiência inédita, à perspectiva singular, que surgia na entrevista, como discutimos acima. No exemplo já citado, quando o entrevistado disse: "Sei lá, que coisa engraçada, eu nunca fui ao psicólogo”, percebíamos uma experiência compartilhada de surpresa e fruição. Um tipo de fala que era indicativa dessa abertura à experiência, e de saída de uma posição de controle, era quando diziam: "está me vindo...", que normalmente era acompanhada de uma lentificação da fala e muitas vezes de um estranhamento. As falas na entrevista, então, conectavam-se a esta experiência que surgia, e não a interpretações sobre ela ou a juízos a respeito de objetos. Entrevistador e entrevistado sentiam-se, enfim, dependentes da experiência de entrevista, de modo que suas falas eram capazes de enunciar esta experiência, ao invés de se constituírem de maneira proprietária e isolada.

\section{Conclusão}

Contemporaneamente as ciências cognitivas têm retomado o interesse pelo estudo da consciência. A pesquisa "O paradigma reconstrutivista da memória: um estudo comparativo das metodologias em primeira e terceira pessoa no domínio da Psicologia da Cognição" tentou contribuir para esse debate.
Afirmamos a relevância de não se tomar a consciência apenas como um objeto a ser observado, como era o caso na introspecção clássica, utilizada no final do século XIX por pesquisadores como Titchener. Buscamos uma estratégia que não reproduzisse o modelo do tribunal, e que considerasse, portanto, os dois sentidos da experiência: vivida e prerrefletida. A entrevista cartográfica que fomos desenvolvendo procurava acolher e acompanhar aquilo que surgia como experiência vivida, na qual a consciência surgia como um dado para um sujeito; no entanto, seu manejo não se fixava nesse vivido e procurava ultrapassá-lo, ampliando os graus de abertura à dimensão da experiência anterior a sua bifurcação em sujeito que experimenta e objeto experimentado. Para tanto, era preciso que o entrevistador também encarnasse na experiência. E a pesquisa era, então, necessariamente intervenção, necessariamente uma configuração de sujeito e objeto.

Os indicadores de movimento - automatismo, controle egoico e autonomia coletiva - nos orientavam nessa condução. Vale relembrar que a autonomia coletiva não era um ponto de chegada, como se tivéssemos ultrapassado os demais. Automatismo, controle egoico e autonomia coletiva intercalavam-se ao longo da entrevista; havia momentos em que um predominava mais do que outro.

Os momentos de autonomia coletiva da experiência da entrevista nos indicaram que é possível cultivar maneiras de pesquisar a cognição mais acolhedoras em relação ao plano comum da experiência. Esta pesquisa foi uma oportunidade de pensarmos a experiência ao mesmo tempo em sua singularidade e em sua dimensão coletiva. Esta dimensão da experiência é doadora de sentido e, diferentemente do plano que denominamos coletivo-social, não está restrita a um ponto de vista. Ao contrário, os pontos de vista são sempre tributários desta dimensão comum. A singularidade da experiência não está referida a indivíduos, mas à experiência mesma. O desenvolvimento e aprofundamento do estudo da entrevista cartográfica pode, assim, vir a contribuir com a construção de abordagens de pesquisa enativas em cognição ${ }^{3}$, que levem em conta os efeitos ético-políticos (de produção de si e de mundo) relativos à experiência.

${ }^{3}$ Em outro campo de interesse da Psicologia, a saúde, esta contribuição já avançou, vide: Mello, Schaeppi, Soares, \& Passos, 2015; Passos, Carvalho \& Milward, 2012; Sade, Renault, Melo, \& Passos, 2013. Sobre o tema da análise nas pesquisas, vide Renault (2015). 


\section{Referências}

Anderson, J. R. (2004) Psicologia cognitiva e suas implicações experimentais. Rio de Janeiro, RJ: LTC.

Belli, R. F. (1989). Influences of misleading postevent information: misinformation interference and acceptance. Journal of Experimental Psychology: General, 118(1), 72-85.

Brown, S. D., \& Reavey, P. (2015). Turning around on experience: The 'expanded view' of memory within psychology. Memory Studies, 8(2), 131-150. https://doi.org/10.1177/1750698014558660

Catania, A. C. (1999) Aprendizagem: Comportamento, linguagem e cognição. Porto Alegre, RS: Artmed.

Depraz, N., Varela, F., \& Vermersch, P. (2006) A redução à prova da experiência. Arquivos Brasileiros de Psicologia, 58(1), 75-86.

Depraz, N., Varela, F., \& Vermersch, P. (2003). On becoming aware: The pragmatics of experiencing. Amsterdan: John Benjamins.

Despret, V. (2011). Os dispositivos experimentais. Fractal:Revista de Psicologia, 23(1), 43-58. https://doi.org/10.1590/ S1984-02922011000100004

Despret, V. (2004). The body we care for: Figures of antropo-zoo-genesis. Body and Society, 10(2-3), 111-134. https:// doi.org/10.1177/1357034X04042938

Eirado, A., Passos, E., Fernandes, C. V. A., Guia, F. R., Ratto, F., ..Vasconcelos, C. S. (2010). Estratégias de pesquisa no estudo da cognição: O caso das falsas lembranças. Psicologia e Sociedade, 22(1), 84 - 94. https://doi.org/10.1590/ S0102-71822010000100011

Eirado, A., Passos, E., Vasconcelos, C. S., Ratto, F., Fernandes, C. V. A., ..., \& Louzada, W. M. (2006). Memória e alteridade: O problema das falsas lembranças. Mnemosine, 2(2), 75-86.

Jack, A \& Roepstorff, A. (2002). Introspection and cognitive brain mapping: From stimulus-response to scriptreport. Trends in Cognitive Sciences, 6(8), 333-339.

Kantowitz, B. H., Roediger III, H., \& Elmes, D. (2006). Psicologia experimental. São Paulo, SP: Thomson Learning.

Kastrup, V., \& Passos, E. (2013). Cartografar é traçar um plano comum. Fractal: Revista de Psicologia, 25(2), 263-280. https://doi.org/10.1590/S1984-02922013000200004

Loftus, E. (1997). Creating false memories. Scientific American, 277, 70-75.

Loftus, E. F., \& Hoffman, H. G. (1989). Misinformation and memory: The creation of new memories. Journal of Experimental Psychology: General, 118(1), 100-104.

Lutz, A., \& Thompson, E. (2003). Neurophenomenology: Integrating subjective experience and brain dynamics in the neuroscience of consciousness. Journal of Consciousness Studies, 10(9-10), 31-52.

Maturana, H. (1997). A ontologia da realidade. Belo Horizonte, MG: UFMG.

Maturana, H., \& Varela, F. (1995). A árvore do conhecimento. Campinas, SP: Psy.

Melo, J., Schaeppi, P., Soares, G., \& Passos, E. (2015). Acesso e compartilhamento da experiência na gestão autônoma da medicação: O manejo cogestivo. Cadernos Humaniza SUS, 5, 233-248.

Middleton, D. (2002). Succession and change in the socio-cultural use of memory: Buiding-in the past in communicative action. Culture \& Psychology, 8(1), 79-95.

Middleton, D., \& Brown, S. D. (2006). A psicologia social da experiência: A relevância da memória. Pro-Posições, 17(2), 71-97.

Overgaard, M., Gallagher S., \& Ramsøy T. Z. (2008). An integration of first-person methodologies in cognitive science. Journal of Consciousness Studies, 15(5), 100-120.

Passos, E., \& Eirado, A. (2009). Cartografia como dissolução do ponto de vista do observador In E. Passos, \& A.Eirado, Pistas do método da cartografia: Pesquisa-intervenção e produção de subjetividade (pp. 110-131). Porto Alegre, RS: Sulina.

Passos, E., Carvalho, S., \& Milward, P. (2012). Experiência de autonomia compartilhada na saúde mental: O “manejo cogestivo" na gestão autônoma da medicação. Pesquisas e Práticas Psicossociais, 7(2), 269-278.

Passos, E., Kastrup, V., \& Escóssia, L. (Org.). (2009) Pistas do método da cartografia: Pesquisa-intervenção e produção de subjetividade. Porto Alegre, RS: Sulina. 
Passos, E., Kastrup, V., \& Tedesco, S. (Org.). (2014) Pistas do método da cartografia: A experiência da pesquisa e o plano comum (Vol. 2). Porto Alegre, RS: Sulina.

Petitmengin, C. (2006). Lénaction comme experience vécue. Intellectica, 43, 85-92.

Petitmengin, C. (2007). Towards the source of thoughts: The gestural and transmodal dimension of lived experience. Journal of Consciousness Studies, 14(3), 54-82.

Petitmengin, C. (2009). Ten years of viewing from within. Exeter: Imprint Academic.

Reavey, P., \& Brown, S. D. (2006). Transforming past agency and action in the present: Time, social remembering and child sexual abuse. Theory and Psychology, 16(2), 179-202. https://doi.org/10.1177/0959354306062535

Renault, L. (2015). A análise em uma pesquisa-intervenção participativa: o caso da gestão autônoma da medicação (Tese de Doutorado). Instituto de Psicologia, Universidade Federal Fluminense, Niterói, RJ, Brasil.

Renault, L., Passos, E., \& Eirado, A. (2016) Da entrevista de explicitação à entrevista na pesquisa cartográfica. In F. S.Amador; M. E. B. Barros, \& T. M. G. Fonseca (Org.). Clínicas do trabalho e paradigma estético (pp. 61-77). Porto Alegre, RS: UFRGS.

Sade, C., Renault, L., Melo, J., \& Passos, E. (2013). O uso da entrevista na pesquisa-intervenção participativa em saúde mental: O dispositivo GAM como entrevista coletiva. Ciência \& Saúde Coletiva, 18(10), 2813-2824. https:// doi.org/10.1590/S1413-81232013001000006

Schacter, D. (2003) Os sete pecados da memória. Rio de Janeiro, RJ: Rocco.

Stein, L. M. (Org.) (2010) Falsas memórias: fundamentos científicos e suas aplicações clínicas e jurídicas. Porto Alegre, RS: Artmed.

Tedesco, S., Sade, C., \& Caliman, L. (2013). A entrevista na pesquisa cartográfica: a experiência do dizer. Fractal: Revista de Psicologia, 25(2), 299-322. https://doi.org/10.1590/S1984-02922013000200006

Varela, F. (1988). Conhecer: As ciências cognitiva : Tendências e perspectivas. Lisboa: Instituto Piaget.

Varela, F. (1989). Autonomie et connaissance. Paris: Seuil.

Varela, F. (1991). Organism: A meshwork of selfless selves. In A. Tauber, Organism and the origins of self(pp. 79-107). Netherlands: Kluwer.

Varela, F. (1996). Neurophenomenology: A methodological remedy for the hard problem. Journal of Consciousness Studies. 3(4), 330-349.

Varela, F. \& Shear, J. (1999). First-person accounts: Why, what, and how. Journal of Consciousness Studies, 6(2-3), 1-14.

Varela, F., Thompson, E., \& Rosch, E. (2003). A mente incorporada: Ciências cognitivas e experiência humana. Porto Alegre, RS: Artmed.

Vermersch, P. (1994). L'entretien d'explicitation. Issy-Les Moulineaux: ESF Editeur.

\section{Eduardo Passos}

Docente do Instituto de Psicologia e do Programa de Pós-graduação em Psicologia da Universidade Federal Fluminense, Niterói - RJ. Brasil.

E-mail : e.passos1956@gmail.com

\section{André do Eirado}

Docente do Instituto de Psicologia da Universidade Federal Fluminense, Niterói - RJ. Brasil.

E-mail : aeirado@gmail.com

\section{Leticia Maria Renault de Barros}

Doutora pelo Programa de Pós-graduação em Psicologia da Universidade Federal Fluminense, Niterói - RJ. Brasil. Pós-doutoranda no Centro de Estudos Sociais da Universidade de Coimbra, Portugal.

E-mail : lerenault@gmail.com 


\section{Christian Sade}

Docente do Departamento de Psicologia da Universidade Federal Fluminense, Rio das Ostras - RJ. Brasil.

E-mail: csade@id.uff.br

Endereço para envio de correspondência:

Rua das Laranjeiras, 226/801. Bairro: Laranjeiras

Cidade: Rio de Janeiro

UF: RJ

CEP: 22240-003

Endereço do Eduardo Passos

Recebido 19/05/2017

Aprovado 20/12/2017

Received 05/19/2017

Approved 12/20/2017

Recibido 19/05/2017

Aceptado 20/12/2017

Como citar: Passos, E., Eirado, A., Renault, L., \& Sade, C. (2018). A entrevista cartográfica na investigação da experiência mnêmica. Psicologia: Ciência e Profissão, 38(2), 275-290. https://doi.org/10.1590/1982-3703001772017

How to cite: Passos, E., Eirado, A., Renault, L., \& Sade, C. (2018). Cartographic interviews in the investigation of mental experiences. Psicologia: Ciência e Profissão, 38(2), 275-290. https://doi.org/10.1590/1982-3703001772017

Cómo citar: Passos, E., Eirado, A., Renault, L., \& Sade, C. (2018). La entrevista cartográfica en la investigación de la experiencia mnémica. Psicologia: Ciência e Profissão, 38(2), 275-290. https://doi.org/10.1590/1982-3703001772017 